\title{
Graves Orbitopathy - an update
}

Wijenayake U. $\mathrm{N}^{1}$, Dissanayake $\mathrm{P}^{1}$, Dematapitiya $\mathrm{C}^{1}$, Pathmanathan $\mathrm{S}^{1}$, Sumanatillake $\mathrm{M}^{1}$, Bulugahapitiya $\mathrm{U}^{1}$

${ }^{1}$ Diabetes and Endocrinology Unit, National Hospital of Sri Lanka

Correspondence email: umeshawijenayake@gmail.com

https://orcid.org/0000-0001-5628-3749

\section{Introduction}

Graves orbitopathy (GO) is the commonest extrathyroidal manifestation of Graves' disease (GD) (1). It's an autoimmune disease characterized by orbital inflammation with subsequent fibrosis and tissue remodeling, resulting in diplopia, proptosis, and in severe cases, optic neuropathy with a significant impact on patients' quality of life (QoL). Knowledge on pathophysiology and therapeutics of GO is evolving, while management remains a major therapeutic and clinical challenge. Current treatment strategies, based on immunosuppression, reduce disease activity and severity in the active inflammatory phase while modifying disease course if initiated at the right time window. Its efficacy is limited in inactive disease, once chronic fibrotic changes are established $(1,3)$. Thus, timely identification and implementation of therapy had a significant impact on the subsequent disease course of GO. This article provides an overview of newer developments of GO epidemiology, pathogenesis, diagnostics, and treatment modalities.

\section{Epidemiology}

The majority $(90 \%)$ of GO patients are hyperthyroid, while $5-10 \%$ are either euthyroid or hypothyroid (4). Similar orbitopathy has also been reported in a few patients with Hashimoto's thyroiditis (5). Considerable differences were noted in GO incidence rates over time. An older study conducted in Minnesota in 1994 demonstrated the age-adjusted incidence of 16/ 100000 population year for wom- en and 2.9/100 000 population year for men. A recent -multicenter prospective study from Sweden in 2011 reported an approximate incidence of 3.3/100 000 population/year in women and 0.9/100 000 population/year in men (6). There is a reduction in incidence rates in newer studies compared to older studies. The difference in classification criteria used or low referral rates leading to an underestimation of incidence is possible, but it could also be a true reduction as a result of improved patient care, referral system, and better risk factor control.

A recently published meta-analysis concluded the overall prevalence of GO is between $25-40 \%$ (7). Early treatment of thyroid dysfunction, use of preventive measures, and risk factor modification may have contributed to the reduced prevalence noted. Recent data demonstrate a higher prevalence of GO among Asians compared to Caucasians, in contradiction to previously published data $(7,8)$. Differences in genetic predisposition or biochemical factors like smoking habits could explain the noted differences.

\section{Immunopathogenesis}

GO is often synchronous with the hyperthyroid phase of GD; at times it follows or precedes the onset of hyperthyroidism (9). TSH receptor (TSH-R) is the major auto-antigen in GO, expressed in orbital fibroblast (OF) surface; overexpression is noted inactive GO (10). TSH receptor antibodies (TRAb) are pathognomonic for GD and positively correlate with disease activity and severity (11,12). TRAb/ 
TSH-R interaction activates an immune cascade leading to infiltration of $\mathrm{T} / \mathrm{B}$ lymphocytes, as well as differentiation of a subset of fibroblasts into adipocytes resulting in enlargement of orbital fat tissue. Inflammatory mediators such as interferon-gamma (IFN- $\gamma$ ), tumor necrosis factor-alpha (TNF- $\beta$ ), interleukin $1 \beta, 2,6,12,16,17$, transforming growth factor $\beta$ (TGF- $\beta$ ), RANTES and neuregulin are released from inflammatory cells. Stimulated OF synthesizes glycosaminoglycans (GAG) like hyaluronic acid which causes local water retention, edema of extraocular muscles and connective tissue.
A subgroup of OF later differentiated into myofibroblasts via TGF- $\beta$ stimulation resulting in fibrosis seen in the inactive phase of the disease (13). Insulin-like growth factor 1 receptor (IGF-1R) is another molecule, drawing a great deal of attention recently due to its therapeutic implications. Its exact role in GO pathogenesis is yet to be confirmed. IGF-1 $\mathrm{R}$ is over-expressed in OF in GO.

It is postulated rather than direct activation through a specific autoantibody, it is involved in the transactivation of TSH-R mediated immune mechanism, as there is a physical and functional interaction between IGF-1R and TSH-R (14).

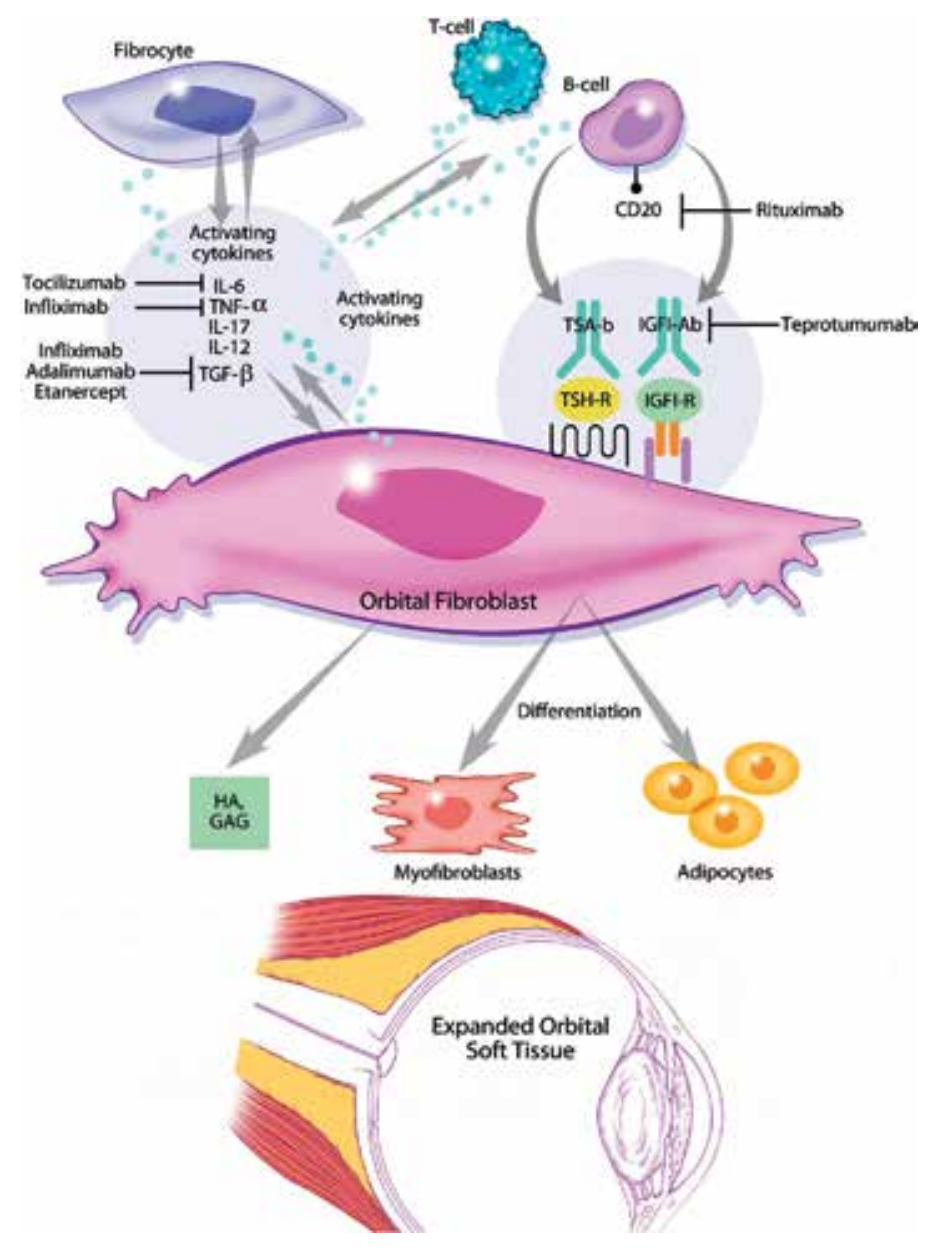

Figure 1 Signaling cascade involved in Graves' orbitopathy (GO) pathogenesis

Hodgson, N.M., Rajaii, F. Current Understanding of the Progression and Management of Thyroid Associated Orbitopathy: A Systematic Review. Ophthalmol Ther 9, 21-33 (2020). https://doi.org/10.1007/s40123-019-00226-9 


\section{Genetics \& Risk factors}

Several immunomodulatory genes are studied in association with GO such as human leukocyte antigen-DR3 (HLA-DR3), interleukin-1 (IL-1), IL-23 receptor (IL-23R), CD40, cytotoxic T lymphocyte antigen (CTLA-4), T-cell receptor B-chain (TCR-B), protein tyrosine phosphatase non-receptor type 22 (PTPN22), tumor necrosis factor- $\beta$ (TNF- $\beta$ ) (15). None of the above polymorphisms provided adequate predictive value to be used as genetic testing. Sexual and ethnic differences noted in disease prevalence could be due yet unidentified genetic association. Smoking is the strongest environmental risk factor associated with GO (16). Smoking cessation decreases the risk of GO development, implying current smoking is more important than lifetime smoking as a risk factor (17) Role of e-cigarettes and passive smoking is yet unsettled (6). Uncontrolled hyper/hypothyroidism, radio-active iodine treatment, oxidative stress, elevated TRAb titters, and hypercholesterolemia are also proven risk factors for the development and progression of GO $(18,19,20,21,22,23)$.

\section{Clinical manifestations and Natural history}

The majority of patients have bilateral symmetrical disease, while some have asymmetric (4-14\%) and unilateral (9-34\%) forms. Asymmetric forms are seen in older men with severe, active disease $(23,24)$. $\mathrm{Eu} /$ hypothyroid GO also has a milder asymmetric disease (26). Reasons for asymmetry are unknown, might be caused by differences in bony anatomy or vascularisation. Unilateral and asymmetrical diseases need careful exclusion of other orbital pathologies mimicking GO.

The natural history of GO was first described by Rundle et al. in 1957, consisting of an active inflammatory phase lasting for 18-36 months (27). Symptoms at this stage include eye pain, grittiness, lacrimation, photophobia, double vision, and blurred vision. Clinical findings include upper eyelid retraction $(70 \%)$, proptosis $(62 \%)$, restrictive myopathy (43\%), lagophthalmos, exposure keratopathy, and corneal ulceration (28).
Dysthyroid optic neuropathy (DON) is a rare $(6 \%)$ sight-threatening complication of active GO (28). Earliest manifestation is color desaturation, followed by reduced visual acuity, visual field defects, and blurred vision (29). Male sex, older age, and smoking were identified risk factors (30). Interestingly a significant proportion of patients had a lower clinical activity score and normal-appearing optic nerves. Colour desaturation and apical muscle crowding were noted in $88 \%$ of the patients (29). Delay in treatment relying on a traditional measure like CAS, fundoscopy may result in irreversible visual loss.

This is followed by a chronic inactive phase characterized by fibrosis. Patients are left with significant disabilities like squints and proptosis. These manifestations are not amenable to immunosuppression, hence require rehabilitative surgery (27). Once inactive disease course is stable, however, $5-16 \%$ of patients may experience a reactivation. Smoking during initial GO, pregnancy, periocular surgery, uncontrolled thyroid dysfunction is recognized risk factors for reactivation (31).

\section{Clinical classification \& Imaging evaluation}

Therapeutic decisions of GO are based on disease activity and severity. In 1989 Mourits et al. proposed a Clinical Activity Score (CAS) to distinguish between active and stable disease (32). The current grading systems used for the assessment of GO are the VISA Classification (vision, inflammation, strabismus, and appearance) and the European Group of Graves' Orbitopathy (EUGOGO) Classification $(33,34)$. Both systems are grounded in the NO SPECS and CAS classifications and use indicators to assess the signs of activity and the degree of severity. More importantly, they allow the clinician to guide the treatment of the patient with GO. VISA is more commonly used in North America and Canada while EUGOGO is in Europe. Since the two protocols are not interchangeable, only one of them should be employed as a reference in a specific patient (35). 


\section{Assessment of activity}

1. Spontaneous retrobulbar pain

2. Pain on attempted upward or downward gaze

3. Redness of eyelids

4. Redness of conjunctiva

5. Swelling of caruncle or plica

6. Swelling of eyelids

7. Swelling of the conjunctiva (chemosis)

Assessment of activity by the clinical activity score (CAS).

CAS $<3=$ inactive GO; CAS $\geq 3=$ active GO. A ten-item CAS, including an increase in exophthal- mos of $\geq 2 \mathrm{~mm}$, a decrease in eye motility of $\geq 8^{\circ}$, or a decrease in visual acuity in the last 1-3 months, is useful to assess the progression of GO after the first visit.

\section{Table 2 Classification of severity of Graves orbitopathy (GO)}

Classification

Mild GO

Moderate-to-severe GO

\section{Features}

Patients whose features of GO have only a minor impact on daily life that have insufficient impact to justify immunomodulation or surgical treatment. They usually have one or more of the following:

- minor lid retraction $(<2 \mathrm{~mm})$

- mild soft-tissue involvement

- exophthalmos

- $<3 \mathrm{~mm}$ above normal for race and gender

- no or intermittent diplopia and corneal exposure responsive to lubricants

Patients without sight-threatening GO whose eye disease has sufficient impact on daily life to justify the risks of immunosuppression (if active) or surgical intervention (if inactive). They usually have two or more of the following:

- $\quad$ lid retraction $\geq 2 \mathrm{~mm}$

- moderate or severe soft-tissue involvement

- exophthalmos $\geq 3 \mathrm{~mm}$ above normal for race and gender

- inconstant or constant diplopia

Sight-threatening (very severe) GO
Patients with dysthyroid optic neuropathy and/or corneal breakdown 
Imaging is important in establishing a diagnosis, differentiation between active and inactive disease, planning surgical decompression, and follow-up (36). Magnetic resonance imaging (MRI) is the investigation of choice as it enables precise soft tissue evaluation, assessment of inflammatory activity (37). Typical MRI findings consist of proptosis, enlargement of the fat content of extraocular muscles, and crowded apex syndrome in cases of DON (38).

Computed tomography (CT) is useful in inactive disease patients, awaiting surgical decompression to describe describe bony anatomy (39).

Color Doppler imaging (CDI), 99mTc-DTPA SPECT/CT have shown promising results in early identification of active disease, with low CAS who would benefit from early immunotherapy $(40,41)$.

\section{Management of GO}

\section{Risk factor modification}

Smoking cessation is the fundamental recommended preventive action. Early diagnosis and treatment of thyroid dysfunction improve GO outcomes $(42,43)$.

Prophylactic steroid cover in mild active GO receiving RAI was effective in the prevention of disease progression. The original dosing regime was oral prednisone $0.3-0.5 \mathrm{mg} / \mathrm{kg}$ started $1-3$ days after RAI treatment for 3 months duration $(43,44)$. Subsequent studies demonstrated a low dose $(0.2$ $\mathrm{mg} / \mathrm{kg}$ ) shorter duration regime of 6 weeks being equally efficacious with few side effects (45). Shiber et al. in 2014 meta-analysis studied the efficacy of 3 tier approach glucocorticoid prophylaxis for GO in RAI, standard-dose prednisone was used in mild-moderate GO, low dose regime in mild GO or no $\mathrm{GO}$ with significant risk factors and no prophylaxis in a patient with no evidence of GO or risk factors with promising results (46). Thus, the guidelines recommend the use of a standard-dose regime in patients with high-risk progression or de-novo development of GO. Low dose regime in patients with low risk (42). However, a recent Japanese randomized trial demonstrated reduced efficacy of low dose regime, making the above recommendation questionable (47).
Recommendations for management inactive $\mathrm{GO}$ in RAI lacks uniformity, the American Thyroid Association guidelines recommend no steroid prophylaxis, whereas European Group of Graves' Orbitopathy (EUGOGO) guidelines state that steroid prophylaxis is not required in the absence of risk factors such as hypothyroidism, high TBII levels or smoking $(42,43,48)$.

\section{General principles of GO management}

Management of GO is based on disease activity, severity, and impact on quality of life. Management decisions should be individualized considering potential risks and benefits $(42,43)$.

Artificial tears alleviate symptoms of corneal irritation. Application of ophthalmic ointments/gels with taping of eyes lids or using swimming goggles in the night is recommended for severe lagophthalmos without an adequate Bell's phenomenon. Protective glasses correct photophobia. Prisms improve diplopia and botulinum toxin is used for temporary control of eyelid retraction in centers of expertise $(42,43)$.

\section{Treatment of mild GO}

Mild GO is a self-limiting disease in the majority thus conservative management strategy is recommended. However, if the impact on QOL outweighs risks, rehabilitative surgery and immunosuppression are justified $(42,43)$.

Selenium supplementation (100 $\mathrm{mcg}$ bd) in mild GO demonstrated improved QoL, less ocular involvement, and slow progression of GO (49). This study was conducted in marginally selenium-deficient regions in Europe, thus its safety and efficacy in Selenium sufficient populations are questionable. As Sri Lankan population is studied to Selenium deficient this therapy could apply to our population (50).

EUGOGO recommends 6 months of selenium supplementation in patients with mild GO for a relatively shorter duration $(42,43)$. However recent evidence suggests it is widely used across Europe as adjuvant therapy in moderate to severe GO as well, in conflict with guideline recommendations (51). 
Active moderate-to-Severe GO management First-line treatment

Systemic glucocorticoids (GC) in combination with mycophenolate mofetil (MMF) is the treatment of choice, preferably carried out in a specialized center. GCs are effective in reducing inflammatory lesions, while the impact on exophthalmos and diplopia is limited $(52,53)$. Intravenous GC are preferred over orals. IV GC demonstrated a $70-80 \%$ response rate compared to $50 \%$ of oral treatment. The adverse event rate is $39 \%$ in IV GC therapy in comparison to $80 \%$ in oral GCs (53-55).

The recommended dose of IV GC is a cumulative dose of $4.5 \mathrm{~g}$ of methylprednisolone given as $12 \times$ weekly infusions $(6 \times 0.5 \mathrm{~g}$ weekly infusions, followed by $6 \times 0.25 \mathrm{~g}$ weekly infusions) $(42,43,55)$. This regime was compared to a shorter course of the same cumulative dose which demonstrated a lower efficacy and higher rate of toxicity (56). 3 different cumulative IV GC doses for GO $(7.47 \mathrm{~g}$, $4.98 \mathrm{~g}$, and $2.25 \mathrm{~g}$ ) over the same duration were studied. The highest dose was associated with higher efficacy and greater toxicity (57). Thus, it is safe to use a 4.5-5g cumulative dose for most patients, while reserving IV GC $0.75 \mathrm{~g}$ weekly for 6 weeks followed by $0.5 \mathrm{~g}$ weekly for 6 weeks for more severe cases.

The morbidity and mortality related to IV GC therapy are reported as $6.5 \%$ and $0.6 \%$ respectively (56). As per safety data single dose should not exceed $0.75 \mathrm{~g}$, cumulative dose should be less than $8 \mathrm{~g}$ and consecutive day therapy avoided unless in patients with sight-threatening GO $(58,59)$.

Mycophenolate Mofetil (MMF) Selectively inhibits DNA replication of T/B lymphocytes (60). Ye X et al. in 2017 demonstrated MMF to be more effective and safer in patients with active moderate to severe GO compared to oral GCs. Apart from CAS, a significant improvement was noted in diplopia and proptosis (61). In 2018 Kahaly et al. compared the efficacy of combination therapy with MMF to GC mono-therapy, where combination therapy was superior with the reduction in relapse rates (62). 'Real-world' safety and efficacy of MMF in moderate-to-severe sight-threatening GO was demonstrated in a 4-year observation study (63).
Thus MMF 0.72g per day for 24 weeks in combination with IV GC is the recommended treatment for patients with moderate-to-severe active GO (43). Studies comparing higher doses of IV GC used in more severe forms of moderate-to-severe GO in combination with MMF are not available. Thus, in such circumstance's higher cumulative dose IV GC (7.5g) mono-therapy is recommended as an alternative approach (43).

\section{Treatment of sight-threatening GO}

3-5\% of patients develop sight-threatening GO, in the form of DON, corneal ulceration, or globe subluxation. In DON immediate treatment with IV methylprednisolone single dose of 500 to $1000 \mathrm{mg}$ for three consecutive days or most preferably for safety reasons on every second day (alternate days) during the first week is recommended. This regime is repeated in the following week as well. If clinical response is insufficient at the end of 2 weeks or significant side effects emerge, immediate decompression surgery should be performed $(42,43)$. This is the only instance where orbital surgery is performed in active GO. Immediate decompression surgery didn't demonstrate superiority over IV GC pulses (64).

Corneal ulceration is managed with blepharorrhaphy, tarsorrhaphy, lid lengthening, extraocular muscle recession, and gluing to protect the cornea. Subluxation of the eyeball is treated with orbital decompression (43).

\section{Active moderate-severe GO management - Second-line treatment}

\section{Orbital radiotherapy}

Radiotherapy has an immunosuppressive effect (65). Retrobulbar RT (20 Gy) is equally efficacious as 3 months oral steroid therapy $(66,67)$. Efficacy and durability are greater when combined with GCs (64). Thus, current recommendation is to combine orbital radiotherapy with either IV or oral GC as a second-line treatment option (43). However, the noted efficacy is controversial due to different radiation protocols and clinical criteria used in trials.

$\mathrm{RT}$ is most beneficial in diplopia (66). Well toler- 
ated and commonly used radiation dose is $20 \mathrm{~Gy}$ (10 doses 2 Gy per eye over 2 weeks), although the good clinical response to a lower dose of $10 \mathrm{~Gy}$ was also noted (65).

Orbital RT can cause a transient exacerbation of eye symptoms ameliorated by concurrent oral GC therapy (70.) Persistent xerophthalmia was noted in about $12 \%$ of patients (71). As it can cause progression of pre-existing retinopathy and carries a remote carcinogenic risk. Thus, uncontrolled diabetes, hypertension, and age less than 35 years are relative contraindications for orbital irradiation $(42,43)$.

\section{Cyclosporine}

It's a calcineurin inhibitor. Monotherapy is not as efficacious as oral GCs. The combined therapy of cyclosporine and oral GCs, in moderate-severe GO, resulted in fewer relapses and higher treatment efficacy. The commonest side effects were dose-dependent hepatotoxicity, nephrotoxicity, and gingival hyperplasia. Though it reduced orbital inflammation long-term improvement of proptosis or strabismus was not seen (72,73). Currently, a combination of oral GC plus Cyclosporine is recommended as a second-line treatment option in moderate-to-severe active GO (43).

\section{Azathioprine}

A 2018 RCT combination of azathioprine and oral prednisolone had a better and long-term clinical outcome compared to GC monotherapy. A combination regime was associated with a reduced relapse rate even after steroid withdrawal (74). Combination of oral GC and Azathioprine is a recommended second-line treatment option in moderate-to-severe active GO (43).

\section{Rituximab}

It's a monoclonal antibody depleting CD20 carrying B lymphocytes (75). In older case reports it was used in patients with active GO unresponsive to IV GCs (76). Salvi et al. demonstrated Rituximab (1000mg weekly for 2 weeks) to have comparable efficacy to IV GCs. Its improved eyeball motility, QoL, and the need for adjuvant surgical treatment
(77). However, in a second study when compared to placebo it failed to demonstrate improved GO outcome (78). Commonly used dose regimes of Rituximab in practice are $1000 \mathrm{mg}-2$ doses 1 week apart or $500 \mathrm{mg}$ single dose (79).

There were reports of DON following Rituximab, thus it is better avoided in patients at risk DON (73). Infusion-related reactions were noted in 10$30 \%$ of patients with the first infusion. Currently, Rituximab is recommended as a second-line treatment option in moderate-to-severe sight-threatening GO (43).

\section{Tocilizumab (TCZ)}

It's a monoclonal antibody against the IL-6 receptor. In a recent randomized interventional study, TCZ mono-therapy decreased CAS, exophthalmos, and improved ocular motility inactive GO patients who are resistant to steroid therapy. No significant side effects were noted. Thus, it can be used as an alternative management option in cases of steroid resistance and is currently a recommended second-line treatment option $(80,43)$.

\section{Teprotumumab}

This is an IGF-1R antagonist with promising results. 2020 OPTIC trial compared Teprotumumab with placebo in patients with moderate to severe active GO. There was a $2 \mathrm{~mm}$ reduction of proptosis in $83 \%$ of the treatment group. The number needed to treat was 1.36, suggesting almost all benefited from therapy. Mean proptosis reduction in the treatment arm was $3 \mathrm{~mm}$ which was comparable to surgery.

In addition, CAS, QoL and diplopia were improved. The drug was well tolerated apart from minor side effects like hyperglycemia, muscle cramps, and hearing impairment (81).

This was offered FDA approval for the management of GO in 2020. Whether this can be used as a first-line agent for GO is questionable. No studies have compared Teprotumumab with GCs which is the current first-line therapy. The safety profile of the molecule is not fully assessed whereas most of 
the side effects of IV GCs are commonly known. Cost is another limiting factor as it is expensive in comparison to steroids. However, as the efficacy is comparable to rehabilitative surgery, it might also be cost-effective in long term (82). Current recommendation is to use Teprotumumab as a second-line treatment option in moderate-to-severe active GO (43).

\section{Somatostatin analogues (SSA)}

Somatostatin receptors were identified on the orbital fibroblast surface (83). Long-acting SSA octreotide was efficacious in reducing orbital soft tissue inflammation thus it was suggested as an alternative in steroid intolerant GO (84). Lanreotride another long-acting SSA, demonstrated similar efficacy, with reduced relapse rates in long-term follow-up (85). A second-generation SSA pasireotide was as effective as IV GC in moderate to severe active GO (86). However, lack of randomized controlled trials and high cost are limiting factors for SSA use in general.

\section{Statins}

HMG-CoA reductase inhibitors are commonly used for the treatment of hyperlipidemia. It also has anti-inflammatory and immunomodulatory effects (87). There is an association between high serum cholesterol levels and GO (23). Statin administration was associated with lower GO occurrence which was not seen in other lipid-lowering drugs (88). Further studies are needed to confirm whether the observed relationship is due to lipid-lowering or anti-inflammatory effects of statins.

\section{Surgical treatment in the management of GO}

Except for sight-threatening GO, surgical interventions are done in the inactive, post-inflammatory phase, at least 6 months after the inflammation has subsided, to correct residual disfigurement and alleviate chronic symptoms $(42,43)$. Rehabilitative surgery; a combination of decompressive surgery, followed by squint surgery and oculoplastic surgery (eyelid strengthening, blepharoplasty) is done sequentially (89-91).

\section{References}

1. Gontarz-Nowak K, Szychlińska M, Matuszewski W， Stefanowicz-Rutkowska M, Bandurska-Stankiewicz E. Current Knowledge on Graves' Orbitopathy. J Clin Med. 2020 Dec 23;10(1):16. doi: 10.3390/jcm10010016. PMID: 33374706; PMCID: PMC7793490.

2. Kalmann R, Mourits MP. Late recurrence of unilateral graves orbitopathy on the contralateral side. Am J Ophthalmol. 2002 May;133(5):7279. doi: 10.1016/s0002-9394(02)01390-9. PMID: 11992884.

3. W. M. Wiersinga (1996) Advances in medical therapy of thyroid-associated ophthalmopathy, Orbit, 15:3, 177-186, DOI: 10.3109/01676839609150235

4. Ponto KA, Binder H, Diana T, Matheis N, Otto AF, Pitz S, Pfeiffer N, Kahaly GJ. Prevalence, Phenotype, and Psychosocial Well-Being in Euthyroid/Hypothyroid Thyroid-Associated Orbitopathy. Thyroid. 2015 Aug;25(8):942-8. doi: 10.1089/ thy.2015.0031. Epub 2015 Jun PMID: 26244413

5. Jain D, Mor S, Aggarwal HK, Chhabra P, Jain P. Thyroid Association Ophthalmopathy in Hashimoto's Thyroiditis: a Case Report. Maedica (Bucur). 2017 Jan;12(1):65-67. PMID: 28878841; PMCID: PMC5574077

6. Bartalena L, Piantanida E, Gallo D, Lai A, Tanda ML. Epidemiology, Natural History, Risk Factors, and Prevention of Graves' Orbitopathy. Front Endocrinol (Lausanne). 2020 Nov 30;11:615993. doi: 10.3389/fendo.2020.615993. PMID: 33329408; PMCID: PMC7734282.

7. Chin $\mathrm{YH}, \mathrm{Ng} \mathrm{CH}$, Lee MH, Koh JWH, Kiew J, Yang SP, Sundar G, Khoo CM. Prevalence of thyroid eye disease in Graves' disease: A meta-analysis and systematic review. Clin Endocrinol (Oxf). 2020 Oct;93(4):363-374. doi: 10.1111/cen.14296. Epub 2020 Aug 10. PMID: 32691849 
8. Tellez M, Cooper J, Edmonds C. Graves' ophthalmopathy in relation to cigarette smoking and ethnic origin. Clin Endocrinol (Oxf). 1992 Mar;36(3):291-4. doi: 10.1111/j.1365-2265.1992. tb01445.x. PMID: 1563082.

9. Wiersinga, W.M., Smit, T., van der Gaag, R. et al. Temporal relationship between onset of Graves' ophthalmopathy and onset of thyroidal Graves' disease. J Endocrinol Invest 11, 615-619 (1988). doi. org/10.1007/BF03350193

10. Wakelkamp IM, Bakker O, Baldeschi L, Wiersinga WM, Prummel MF. TSH-R expression and cytokine profile in orbital tissue of active vs. inactive Graves' ophthalmopathy patients. Clin Endocrinol (Oxf). 2003 Mar;58(3):280-7. doi: 10.1046/j.13652265.2003.01708.x. PMID: 12608932

11. Khoo DH, Eng PH, Ho SC, Tai ES, Morgenthaler NG, Seah LL, Fong KS, Chee SP, Choo CT, Aw SE. Graves'ophthalmopathy in the absence of elevated free thyroxine and triiodothyronine levels: prevalence, natural history, and thyrotropin receptor antibody levels. Thyroid. 2000 Dec;10(12):1093-100. doi: 10.1089/thy.2000.10.1093. PMID: 11201855.

12. Gerding $\mathrm{MN}$, van der Meer JW, Broenink M, Bakker O, Wiersinga WM, Prummel MF. Association of thyrotrophin receptor antibodies with the clinical features of Graves' ophthalmopathy. Clin Endocrinol (Oxf). 2000 Mar;52(3):267-71. doi: 10.1046/j.1365-2265.2000.00959.x. PMID: 10718823.

13. Bahn RS. Graves' ophthalmopathy. N Engl J Med. 2010 Feb 25;362(8):726-38. doi: 10.1056/ NEJMra0905750. PMID: 20181974; PMCID: PMC3902010.

14. Tsui S, Naik V, Hoa N, Hwang CJ, Afifiyan NF, Sinha Hikim A, Gianoukakis AG, Douglas RS, Smith TJ. Evidence for an association between thyroid-stimulating hormone and insulin-like growth factor 1 receptors: a tale of two anti- gens implicated in Graves' disease. J Immunol. 2008 Sep 15;181(6):4397-405. doi: 10.4049/jimmunol.181.6.4397. PMID: 18768899; PMCID: PMC2775538.

15. Khalilzadeh O, Noshad S, Rashidi A, Amirzargar A. Graves' ophthalmopathy: a review of immunogenetics. Curr Genomics. 2011 Dec;12(8):56475. doi: 10.2174/138920211798120844. PMID: 22654556; PMCID: PMC3271309.

16. Bartalena L, Piantanida E. Cigarette smoking: number one enemy for Graves ophthalmopathy. Pol Arch Med Wewn. 2016 Oct 28;126(10):725726. doi: 10.20452/pamw.3592. Epub 2016 Oct 28. PMID: 27872448.

17. Pfeilschifter J, Ziegler R. Smoking and endocrine ophthalmopathy: impact of smoking severity and current vs lifetime cigarette consumption. Clin Endocrinol (Oxf). 1996 Oct;45(4):477-81. doi: 10.1046/j.1365-2265.1996.8220832.x. PMID: 8959089.

18. Wiersinga WM, Bartalena L. Epidemiology and prevention of Graves' ophthalmopathy. Thyroid. 2002 Oct;12(10):855-60. doi: 10.1089/105072502761016476. PMID: 12487767

19. Bartalena L, Marcocci C, Bogazzi F, Manetti L, Tanda ML, Dell'Unto E, Bruno-Bossio G, Nardi M, Bartolomei MP, Lepri A, Rossi G, Martino E, Pinchera A. Relation between therapy for hyperthyroidism and the course of Graves' ophthalmopathy. N Engl J Med. 1998 Jan 8;338(2):73-8. doi: 10.1056/NEJM199801083380201. PMID: 9420337.

20. Bartalena L, Tanda ML, Piantanida E, Lai A. Oxidative stress and Graves' ophthalmopathy: in vitro studies and therapeutic implications. Biofactors. 2003;19(3-4):155-63. doi: 10.1002/ biof.5520190308. PMID: 14757966. 
21. Eckstein AK, Plicht M, Lax H, Neuhäuser M, Mann K, Lederbogen S, Heckmann C, Esser J, Morgenthaler NG. Thyrotropin receptor autoantibodies are independent risk factors for Graves' ophthalmopathy and help to predict severity and outcome of the disease. J Clin Endocrinol Metab. 2006 Sep;91(9):3464-70. doi: 10.1210/jc.20052813. Epub 2006 Jul 11. PMID: 16835285

22. Sabini E, Mazzi B, Profilo MA, Mautone T, Casini $\mathrm{G}$, Rocchi R, et al. High serum cholesterol is a novel risk factor for Graves' orbitopathy: results of a cross-sectional study. Thyroid (2018) 28:386-94. doi: 10.1089/thy.2017.0430

23. Lanzolla G, Sabini E, Profilo MA, Mazzi B, Sframeli A, Rocchi R, Menconi F, Leo M, Nardi M, Vitti P, Marcocci C, Marinò M. Relationship between serum cholesterol and Graves' orbitopathy (GO): a confirmatory study. J Endocrinol Invest. 2018 Dec;41(12):1417-1423. doi: 10.1007/s40618018-0915-z. Epub 2018 Jun 19. PMID: 29923059.

24. Perros P, Zarkovic MP, Panagiotou GC, Azzolini C, Ayvaz G, Baldeschi L, et al. Asymmetry indicates more severe and active disease in Graves' orbitopathy: results from a prospective cross-sectional multicentre study. J Endocrinol Invest (2020) 43:1717-22. doi: 10.1007/s40618-020-01258-w

25. Daumerie C, Duprez T, Boschi A. Long-term multidisciplinary follow-up of unilateral thyroid-associatedorbitopathy. Eur J Intern Med (2008) 19:531-6. doi: 10.1016/j.ejim.2008.01.01

26. Eckstein AK, Losch C, Glowacka D, Schott M, Mann K, Esser J, et al. Euthyroid and primarily hypothyroid patients develop milder and significantly more asymmetrical Graves ophthalmopathy. Br J Ophthalmol (2009) 93:1052-6. doi: 10.1136/ bjo. 2007.137265

27. Rundle FF, Wilson CW. Development and course of exophthalmos and ophthalmoplegia in Graves' disease with special reference to the effect of thy- roidectomy. Clin Sci. 1945;5(3-4):177-94. PMID: 21011937.

28. Bartley GB, Fatourechi V, Kadrmas EF, Jacobsen SJ, Ilstrup DM, Garrity JA, Gorman CA. Clinical features of Graves' ophthalmopathy in an incidence cohort. Am J Ophthalmol. 1996 Mar;121(3):28490. doi: 10.1016/s0002-9394(14)70276-4. PMID: 8597271.

29. McKeag D, Lane C, Lazarus JH, Baldeschi L, Boboridis K, Dickinson AJ, Hullo AI, Kahaly G, Krassas G, Marcocci C, Marinò M, Mourits MP, Nardi M, Neoh C, Orgiazzi J, Perros P, Pinchera A, Pitz S, Prummel MF, Sartini MS, Wiersinga WM; European Group on Graves' Orbitopathy (EUGOGO). Clinical features of dysthyroid optic neuropathy: a European Group on Graves' Orbitopathy (EUGOGO) survey. Br J Ophthalmol. 2007 Apr;91(4):4558. doi: 10.1136/bjo.2006.094607. Epub 2006 Oct 11. PMID: 17035276; PMCID: PMC1994756.

30. Trobe JD, Glaser JS, Laflamme P. Dysthyroid optic neuropathy. Clinical profile and rationale for management. Arch Ophthalmol. 1978 Jul;96(7):1199-1209. doi: 10.1001/archopht.1978.03910060033007. PMID: 666628

31. Selva D, Chen C, King G. Late reactivation of thyroid orbitopathy. Clin Exp Ophthalmol. 2004 Feb;32(1):46-50. doi: 10.1046/j.14429071.2004.00756.x. PMID: 14746591

32. Mourits MP, Koornneef L, Wiersinga WM, Prummel MF, Berghout A, van der Gaag R. Clinical criteria for the assessment of disease activity in Graves' ophthalmopathy: a novel approach. Br J Ophthalmol. 1989 Aug;73(8):639-44. doi: 10.1136/bjo.73.8.639. PMID: 2765444; PMCID: PMC1041835

33. European Group on Graves’ Orbitopathy (EUGOGO), Wiersinga WM, Perros P, Kahaly GJ, Mourits MP, Baldeschi L, Boboridis K, Boschi A, Dickinson AJ, Kendall-Taylor P, Krassas GE, Lane 
CM, Lazarus JH, Marcocci C, Marino M, Nardi M, Neoh C, Orgiazzi J, Pinchera A, Pitz S, Prummel MF, Sartini MS, Stahl M, von Arx G. Clinical assessment of patients with Graves' orbitopathy: the European Group on Graves' Orbitopathy recommendations to generalists, specialists and clinical researchers. Eur J Endocrinol. 2006 Sep;155(3):3879. doi: 10.1530/eje.1.02230. PMID: 16914591.

34. Dolman PJ. Grading Severity and Activity in Thyroid Eye Disease. Ophthalmic Plast Reconstr Surg. 2018 Jul/Aug;34(4S Suppl 1):S34-S40. doi: 10.1097/IOP.0000000000001150. PMID: 29952931.

35. Jesús Barrio-Barrio, Alfonso L. Sabater, Elvira Bonet-Farriol, Álvaro Velázquez-Villoria, Juan C. Galofré, “Graves' Ophthalmopathy: VISA versus EUGOGO Classification, Assessment, and Management", Journal of Ophthalmology, vol. 2015, Article ID 249125, 16 pages, 2015. doi. org/10.1155/2015/249125

36. Gonçalves AC, Gebrim EM, Monteiro ML. Imaging studies for diagnosing Graves' orbitopathy and dysthyroid optic neuropathy. Clinics (Sao Paulo). 2012 Nov;67(11):1327-34. doi: 10.6061/ clinics/2012(11)18. PMID: 23184212; PMCID: PMC3488994.

37. Kahaly GJ. Imaging in thyroid-associated orbitopathy. Eur J Endocrinol. 2001 Aug;145(2):107-18. doi: 10.1530/ eje.0.1450107. PMID: 11454505.

38. Müller-Forell W, Kahaly GJ. Neuroimaging of Graves' orbitopathy. Best Pract Res Clin Endocrinol Metab. 2012 Jun;26(3):259-71. doi: 10.1016/j. beem.2011.11.009. PMID: 22632363.

39. Kirsch, E.; Hammer, B. Graves'orbitopathy: Current imaging procedures. Swiss Med. Wkely. 2009, 139, 618-623

40. Monteiro ML, Moritz RB, Angotti Neto H, Ben- abou JE. Color Doppler imaging of the superior ophthalmic vein in patients with Graves' orbitopathy before and after treatment of congestive disease. Clinics (Sao Paulo). 2011;66(8):1329-34. doi: 10.1590/s1807-59322011000800004. PMID: 21915479; PMCID: PMC316120

41. Liu D, Xu X, Wang S, Jiang C, Li X, Tan J, Deng Z. 99mTc-DTPA SPECT/CT provided guide on triamcinolone therapy in Graves' ophthalmopathy patients. Int Ophthalmol. 2020 Mar;40(3):553-561. doi: 10.1007/s10792-019-01213-6. Epub 2019 Dec 2. PMID: 31792849.

42. Bartalena L, Baldeschi L, Boboridis K, Eckstein A, Kahaly GJ, Marcocci C, Perros P, Salvi M, Wiersinga WM; European Group on Graves' Orbitopathy (EUGOGO). The 2016 European Thyroid Association/European Group on Graves' Orbitopathy Guidelines for the Management of Graves' Orbitopathy. Eur Thyroid J. 2016 Mar;5(1):9-26. doi: 10.1159/000443828. Epub 2016 Mar 2. PMID: 27099835; PMCID: PMC4836120

43. Bartalena, L., Kahaly, G. J., Baldeschi, L., Dayan, C. M., Eckstein, A., Marcocci, C., Marinò, M., Vaidya, B., Wiersinga, W. M., \& EUGOGO. (2021). The 2021 European Group on Graves' orbitopathy (EUGOGO) clinical practice guidelines for the medical management of Graves' orbitopathy, European Journal of Endocrinology, 185(4), G43-G67. Retrieved Oct 25, 2021, from https://eje.bioscientifica.com/view/journals/eje/185/4/EJE-210479.xml

44. Bartalena L, Marcocci C, Bogazzi F, Manetti L, Tanda ML, Dell'Unto E, Bruno-Bossio G, Nardi M, Bartolomei MP, Lepri A, Rossi G, Martino E, Pinchera A. Relation between therapy for hyperthyroidism and the course of Graves' ophthalmopathy. N Engl J Med.1998 Jan 8;338(2):738. doi: 10.1056/NEJM199801083380201. PMID: 9420337.

45. Adriana Lai, Lorenza Sassi, Emanuele Compri, 
Franca Marino, Paolo Sivelli, Eliana Piantanida, Maria Laura Tanda, Luigi Bartalena, Lower Dose Prednisone Prevents Radioiodine-Associated Exacerbation of Initially Mild or Absent Graves' Orbitopathy: A Retrospective Cohort Study, The Journal of Clinical Endocrinology \& Metabolism, Volume 95, Issue 3, 1 March 2010, Pages 1333-1337

46. Shiber S, Stiebel-Kalish H, Shimon I, Grossman A, Robenshtok E. Glucocorticoid regimens for prevention of Graves' ophthalmopathy progression following radioiodine treatment: systematic review and meta-analysis. Thyroid. 2014 Oct;24(10):151523. doi: 10.1089/thy.2014.0218. Epub 2014 Aug 22. PMID: 25068172.

47. Watanabe N, Noh JY, Kozaki A, Iwaku K, Sekiya K, Kosuga Y, Matsumoto M, Suzuki M, Yoshihara A, Ohye H, Kobayashi S, Kunii Y, Mukasa K, Sugino K, Inoue T, Ito K. Radioiodine-Associated Exacerbation of Graves' Orbitopathy in the Japanese Population: Randomized Prospective Study. J Clin Endocrinol Metab. 2015 Jul;100(7):2700-8. doi: 10.1210/jc.2014-4542. Epub 2015 May 12. PMID: 25965082.

48. Bahn RS, Burch HB, Cooper DS, Garber JR, Greenlee MC, Klein I, Laurberg P, McDougall IR, Montori VM, Rivkees SA, Ross DS, Sosa JA, Stan MN; American Thyroid Association; American Association of Clinical Endocrinologists. Hyperthyroidism and other causes of thyrotoxicosis: management guidelines of the American Thyroid Association and American Association of Clinical Endocrinologists. Endocr Pract. 2011 MayJun;17(3):456-520. doi: 10.4158/ep.17.3.456. Erratum in: Endocr Pract. 2013 Mar-Apr;19(2):384. PMID: 21700562.

49. Marcocci C, Kahaly GJ, Krassas GE, Bartalena L, Prummel M, Stahl M, Altea MA, Nardi M, Pitz S, Boboridis K, Sivelli P, von Arx G, Mourits MP, Baldeschi L, Bencivelli W, Wiersinga W; European Group on Graves' Orbitopathy. Selenium and the course of mild Graves' orbitopathy. N Engl J Med. 2011 May 19;364(20):1920-31. doi: 10.1056/NEJMoa1012985. PMID: 21591944

50. Abeywickrama HM, Koyama Y, Uchiyama M, Shimizu U, Iwasa Y, Yamada E, Ohashi K, Mitobe Y. Micronutrient Status in Sri Lanka: A Review. Nutrients. 2018 Oct 27;10(11):1583. doi: 10.3390/nu10111583. PMID: 30373264; PMCID: PMC6265675

51. Negro R, Hegedüs L, Attanasio R, Papini E, Winther K, H: A 2018 European Thyroid Association Survey on the Use of Selenium Supplementation in Graves' Hyperthyroidism and Graves' Orbitopathy. Eur Thyroid J 2019;8:7-15. doi: 10.1159/000494837

52. van Geest RJ, Sasim IV, Koppeschaar HP, Kalmann R, Stravers SN, Bijlsma WR, Mourits MP. Methylprednisolone pulse therapy for patients with moderately severe Graves' orbitopathy: a prospective, randomized, placebo-controlled study. Eur J Endocrinol. 2008 Feb;158(2):229-37. doi: 10.1530/EJE-07-0558. PMID: 18230831.

53. Zang S, Ponto KA, Kahaly GJ. Clinical review: Intravenous glucocorticoids for Graves' orbitopathy: efficacy and morbidity. J Clin Endocrinol Metab. 2011 Feb;96(2):320-32. doi: 10.1210/jc.2010-1962. Epub 2011 Jan 14. PMID: 21239515.

54. Stiebel-Kalish H, Robenshtok E, Hasanreisoglu M, Ezrachi D, Shimon I, Leibovici L. Treatment modalities for Graves' ophthalmopathy: systematic review and metaanalysis. J Clin Endocrinol Metab. 2009 Aug;94(8):2708-16. doi: 10.1210/jc.20090376. Epub 2009 Jun 2. PMID: 19491222

55. Kahaly GJ, Pitz S, Hommel G, Dittmar M. Randomized, single blind trial of intravenous versus oral steroid monotherapy in Graves' orbitopathy. J Clin Endocrinol Metab. 2005 Sep;90(9):523440. doi: 10.1210/jc.2005-0148. Epub 2005 Jul 5. 
PMID: 15998777.

56. Zhu W, Ye L, Shen L, Jiao Q, Huang F, Han R, Zhang X, Wang S, Wang W, Ning G. A prospective, randomized trial of intravenous glucocorticoids therapy with different protocols for patients with graves' ophthalmopathy. J Clin Endocrinol Metab. 2014 Jun;99(6):1999-2007. doi: 10.1210/jc.20133919. Epub 2014 Feb 28. PMID: 24606088.

57. Bartalena L, Krassas GE, Wiersinga W, Marcocci C, Salvi M, Daumerie C, Bournaud C, Stahl M, Sassi L, Veronesi G, Azzolini C, Boboridis KG, Mourits MP, Soeters MR, Baldeschi L, Nardi M, Currò N, Boschi A, Bernard M, von Arx G; European Group on Graves' Orbitopathy. Efficacy and safety of three different cumulative doses of intravenous methylprednisolone for moderate to severe and active Graves' orbitopathy. J Clin Endocrinol Metab. 2012 Dec;97(12):4454-63. doi: 10.1210/ jc.2012-2389. Epub 2012 Oct 4. PMID: 23038682.

58. Zang S, Ponto KA, Pitz S, Kahaly GJ. Dose of intravenous steroids and therapy outcome in Graves' orbitopathy. J Endocrinol Invest. 2011 Dec;34(11):876-80. doi: 10.1007/BF03346732. PMID: 22322535

59. Riedl M, Kolbe E, Kampmann E, Krämer I, Kahaly GJ. Prospectively recorded and MedDRA-coded safety data of intravenous methylprednisolone therapy in Graves' orbitopathy. J Endocrinol Invest. 2015 Feb;38(2):177-82. doi: 10.1007/s40618014-0227-x. Epub 2015 Jan 10. PMID: 25576458.

60. Allison A. Mechanisms of action of mycophenolate mofetil. Lupus. 2005;14(3_suppl):2-8. doi:10.1191/0961203305LU2109OA

61. Ye X, Bo X, Hu X, Cui H, Lu B, Shao J, Wang J. Efficacy and safety of mycophenolate mofetil in patients with active moderate-to-severe Graves' orbitopathy. Clin Endocrinol (Oxf). 2017 Feb;86(2):247-255. doi: 10.1111/cen.13170. Epub 2016 Sep 7. PMID: 27484048.
62. Kahaly GJ, Riedl M, König J, Pitz S, Ponto K, Diana T, Kampmann E, Kolbe E, Eckstein A, Moeller LC, Führer D, Salvi M, Curro N, Campi I, Covelli D, Leo M, Marinò M, Menconi F, Marcocci C, Bartalena L, Perros P, Wiersinga WM; European Group on Graves’ Orbitopathy (EUGOGO). Mycophenolate plus methylprednisolone versus methylprednisolone alone in active, moderate-to-severe Graves’ orbitopathy (MINGO): a randomised, observer-masked, multicentre trial. Lancet Diabetes Endocrinol. 2018 Apr;6(4):287298. doi: 10.1016/S2213-8587(18)30020-2. Epub 2018 Jan 31. PMID: 29396246

63. Quah Qin Xian N, Alnahrawy A, Akshikar R, Lee V. Real-World Efficacy and Safety of Mycophenolate Mofetil in Active Moderate-to-Sight-Threatening Thyroid Eye Disease. Clin Ophthalmol. 2021 May 10;15:1921-1932. doi: 10.2147/OPTH.S305717. PMID: 34007144; PMCID: PMC8121682.

64. Wakelkamp IM, Baldeschi L, Saeed P, Mourits MP, Prummel MF, Wiersinga WM. Surgical or medical decompression as a first-line treatment of optic neuropathy in Graves' ophthalmopathy? A randomized controlled trial. Clin Endocrinol (Oxf). 2005 Sep;63(3):323-8. doi: 10.1111/j.13652265.2005.02345.x. PMID: 16117821.

65. Arenas M, Sabater S, Hernández V, Rovirosa A, Lara PC, Biete A, Panés J. Anti-inflammatory effects of low-dose radiotherapy. Indications, dose, and radiobiological mechanisms involved. Strahlenther Onkol. 2012 Nov;188(11):975-81. doi: 10.1007/s00066-012-0170-8. Epub 2012 Aug 22. PMID: 22907572.

66. Prummel, M.F.; Berghout, A.; Wiersinga, W.M.; Mourits, M.P.; Koornneef, L.; Blank, L. Randomised double-blind trial of prednisone versus radiotherapy in Graves' ophthalmopathy. Lancet 1993, 342, 949-954

67. Gorman CA, Garrity JA, Fatourechi V, Bahn RS, Petersen IA, Stafford SL, Earle JD, Forbes GS, 
Kline RW, Bergstralh EJ, Offord KP, Rademacher DM, Stanley NM, Bartley GB. A prospective, randomized, double-blind, placebo-controlled study of orbital radiotherapy for Graves' ophthalmopathy. Ophthalmology. 2001 Sep;108(9):1523-34. doi: 10.1016/s0161-6420(01)00632-7. Erratum in: Ophthalmology. 2004 Jul;111(7):1306. PMID: 11535445.

68. Ng, C.M.; Yuen, H.K.L.; Choi, K.L.; Chan, M.K.; Yuen, K.T.; Ng, Y.W.; Tiu, S.C. Combined orbital irradiation and systemic steroids compared with systemic steroids alone in the management of moderate-to-severe Graves' ophthalmopathy: A preliminary study. Hong Kong Med. J. 2005, 11, 322-330.

69. Kahaly GJ, Rösler HP, Pitz S, Hommel G. Lowversus high-dose radiotherapy for Graves' ophthalmopathy: a randomized, single blind trial. J Clin Endocrinol Metab. 2000 Jan;85(1):102-8. doi: 10.1210/jcem.85.1.6257. PMID: 10634372.

70. San Miguel I, Arenas M, Carmona R, Rutllan J, Medina-Rivero F, Lara P. Review of the treatment of Graves' ophthalmopathy: The role of the new radiation techniques. Saudi J Ophthalmol. 2018 Apr-Jun;32(2):139-145. doi: 10.1016/j. sjopt.2017.09.003. Epub 2017 Sep 21. PMID: 29942184; PMCID: PMC6010590.

71. Bartalena L, Marcocci C, Tanda ML, Rocchi R, Mazzi B, Barbesino G, Pinchera A. Orbital radiotherapy for Graves' ophthalmopathy. Thyroid. 2002 Mar;12(3):245-50. doi: 10.1089/105072502753600223. PMID: 11952048.

72. Prummel MF, Mourits MP, Berghout A, Krenning EP, van der Gaag R, Koornneef L, Wiersinga WM. Prednisone and cyclosporine in the treatment of severe Graves' ophthalmopathy. N Engl J Med. 1989 Nov 16;321(20):1353-9. doi: 10.1056/ NEJM198911163212002. PMID: 2519530.
Meuer S, Muller W, Dennebaum R, Beyer J. Ciclosporin and prednisone v. prednisone in treatment of Graves' ophthalmopathy: a controlled, randomized and prospective study. Eur J Clin Invest. 1986 Oct;16(5):415-22. doi: 10.1111/j.1365-2362.1986. tb01016.x. PMID: 3100309.

74. Rajendram, R.; Taylor, P.N.; Wilson, V.J.; Harris, N.; Morris, O.C.; Tomlinson, M.; Yarrow, S.; Garrott, H.; Herbert, H.M.; Dick, A.D.; et al. Combined immunosuppression and radiotherapy in thyroid eye disease (CIRTED): A multicentre, $2 \times 2$ factorial, double-blind, randomised controlled trial. Lancet Diabetes Endocrinol. 2018, 6, 299-309

75. Emer, J.J.; Claire, W. Rituximab. J. Clin. Aesthet. Dermatol. 2009, 2, 29-37.

76. Salvi M, Vannucchi G, Campi I, Rossi S, Bonara P, Sbrozzi F, Guastella C, Avignone S, Pirola G, Ratiglia R, Beck-Peccoz P. Efficacy of rituximab treatment for thyroid-associated ophthalmopathy as a result of intraorbital B-cell depletion in one patient unresponsive to steroid immunosuppression. Eur J Endocrinol. 2006 Apr;154(4):511-7. doi: 10.1530/eje.1.02119. PMID: 16556712.

77. Salvi M, Vannucchi G, Currò N, Campi I, Covelli D, Dazzi D, Simonetta S, Guastella C, Pignataro L, Avignone S, Beck-Peccoz P. Efficacy of B-cell targeted therapy with rituximab in patients with active moderate to severe Graves' orbitopathy: a randomized controlled study. J Clin Endocrinol Metab. 2015 Feb;100(2):422-31. doi: 10.1210/jc.2014-3014. Epub 2014 Dec 15. PMID: 25494967; PMCID: PMC4318899

78. Stan MN, Garrity JA, Carranza Leon BG, Prabin T, Bradley EA, Bahn RS. Randomized controlled trial of rituximab in patients with Graves' orbitopathy. J Clin Endocrinol Metab. 2015 Feb;100(2):432-41. doi: 10.1210/jc.2014-2572. Epub 2014 Oct 24. PMID: 25343233; PMCID: PMC4318907.

73. Kahaly G, Schrezenmeir J, Krause U, Schweikert B, 79. Ostrowski RA, Bussey MR, Shayesteh Y, Jay 
WM. Rituximab in the Treatment of Thyroid Eye Disease: A Review. Neuroophthalmology. 2015 Jun 17;39(3):109-115. doi: 10.3109/01658107.2015.1039140. PMID: 27928343; PMCID: PMC5123122.

80. Pérez-Moreiras JV, Alvarez-López A, Gómez EC. Treatment of active corticosteroid-resistant graves' orbitopathy. Ophthalmic Plast Reconstr Surg. 2014 Mar-Apr;30(2):162-7. doi: 10.1097/ IOP.0000000000000037. PMID: 24503568.

81. Douglas RS, Kahaly GJ, Patel A, Sile S, Thompson EHZ, Perdok R, Fleming JC, Fowler BT, Marcocci C, Marinò M, Antonelli A, Dailey R, Harris GJ, Eckstein A, Schiffman J, Tang R, Nelson C, Salvi M, Wester S, Sherman JW, Vescio T, Holt RJ, Smith TJ. Teprotumumab for the Treatment of Active Thyroid Eye Disease. N Engl J Med. 2020 Jan 23;382(4):341-352. doi: 10.1056/NEJMoa1910434. PMID: 31971679

82. Ozzello DJ, Dallalzadeh LO, Liu CY. Teprotumumab for chronic thyroid eye disease. Orbit. 2021 Jun 1:1-8. doi: 10.1080/01676830.2021.1933081. Epub ahead of print. PMID: 34060414.

83. Bartalena L, Pinchera A, Marcocci C. Management of Graves' ophthalmopathy: reality and perspectives. Endocr Rev. 2000 Apr;21(2):168-99. doi: 10.1210/edrv.21.2.0393. PMID: 10782363.
84. Kung, A.W.; Michon, J.; Tai, K.S.; Chan, F.L. The effect of somatostatin versus corticosteroid in the treatment of Graves' ophthalmopathy. Thyroid 1996, 6, 381-384

85. Pilarska, K.; Kulig, G. Lanreotide in the treatment of thyroid orbitopathy. Pr. Lek. 2004, 61, 845847

86. Le, M.R.; Castoro, C.; Mouritz, M.; Souters, M. Pasireotide and Graves; Bio Scientifica: Rome, Italy, 2018.

87. Jain, M., Ridker, P. Anti-Inflammatory Effects of Statins: Clinical Evidence and Basic Mechanisms. Nat Rev Drug Discov 4, 977-987 (2005). doi. org/10.1038/nrd1901

88. Lanzolla G, Vannucchi G, Ionni I, Campi I, Sileo F, Lazzaroni E, Marinò M. Cholesterol Serum Levels and Use of Statins in Graves' Orbitopathy: A New Starting Point for the Therapy. Front Endocrinol (Lausanne). 2020 Jan 22;10:933. doi: 10.3389/ fendo.2019.00933. PMID: 32038490; PMCID: PMC6987298.

89. Eckstein,A.;Schittkowski,M.;Esser,J.Surgicaltreatment of Graves' ophthalmopathy. Bes tPract.Res. Clin.Endocrinol.Metab. 2012, 26, 339-358 